\title{
Effect of local exercise and vessel occlusion on fibrinolytic activity
}

\author{
J. A. N. RENNIE, B. BENNETT, AND D. OGSTON \\ From the Department of Medicine, University of Aberdeen, Aberdeen, Scotland
}

SUMMARY Arterial occlusion of the upper limb did not affect the fibrinolytic activity in the venous blood of that limb; venous occlusion associated with venous distension resulted in a marked rise in activity. Local fibrinolytic activity was increased substantially by active exercise; passive exercise induced a smaller increase. Active exercise undertaken during arterial occlusion did not result in a rise in activator level. It is concluded from these results that blood flow into the venous system rather than accumulation of metabolites is responsible for the increased release of activator into the blood during local exercise and vessel occlusion.

Blood fibrinolytic activity is enhanced by physical exertion (Biggs et al., 1947; Sherry et al., 1959; Ogston and Fullerton, 1961) and by venous occlusion (Clarke et al., 1960). It is widely accepted that the vascular endothelium is the source of the plasminogen activator which is responsible for blood fibrinolytic activity, but the mechanism underlying the release of activator is not established. In an attempt to further our understanding of this mechanism we have studied the induction of local fibrinolytic activity by passive and active exercise and by venous and arterial occlusion.

\section{Methods}

Fibrinolytic activity was measured by the euglobulin clot lysis time method (Nilsson and Olow, 1962) using a clot lysis time recorder (Carmanan Instrumentation Ltd, Glasgow). The results are expressed by plotting the lysis times logarithmically against units of fibrinolytic activity (Sherry et al., 1959), 10 units being arbitrarily equated with a lysis time of 50 minutes. This technique reflects primarily levels of plasminogen activator.

Passive exercise consisted of passive wrist flexion to $90^{\circ}$ every 2.5 seconds for a period of 3 minutes.

Active exercise consisted of active wrist flexion to $90^{\circ}$ every 2.5 seconds for a period of 3 minutes.

Venous occlusion was achieved by inflating a sphygmomanometer cuff on the upper arm to midway between the diastolic and systolic blood pressure for a period of 3 minutes.

Received for publication 6 September 1976
Arterial occlusion was achieved by inflating a sphygmomanometer cuff on the upper arm to above the systolic blood pressure for a period of 3 minutes.

The subjects were healthy volunteers, medical students, and colleagues.

\section{Results}

ACTIVE AND PASSIVE LOCAL EXERCISE

The effect of active exercise and passive exercise was tested in seven subjects. The individual results for

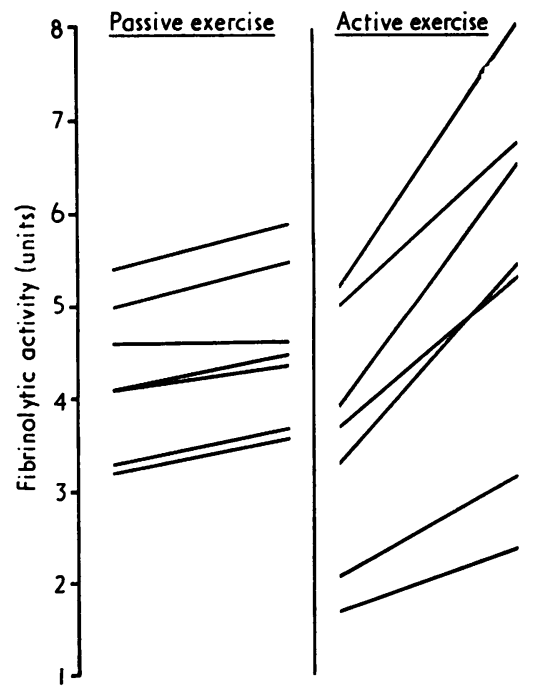

Figure Effect of active and passive exercise for 3 minutes on fibrinolytic activity. 
active and passive exercise experiments are shown in the Figure. The mean increase induced by passive exercise was 0.36 unit with a mean increase of 1.87 units resulting from active exercise. Both increases were statistically significant (active exercise: $P<$ 0.001; passive exercise: $P<0.005$ ).

\section{ARTERIAL AND VENOUS OCCLUSION}

The effect of arterial occlusion and of venous occlusion on the induction of local fibrinolytic activity was tested in four subjects; the blood samples were withdrawn from all subjects at the end of the period of arterial or venous occlusion but before release of the tourniquet, and a control sample was withdrawn simultaneously from the opposite arm. Arterial occlusion for 3 minutes induced no increase in fibrinolytic activity in any subject whereas venous occlusion induced a marked increase in all the subjects tested (Table 1). In subsequent experiments samples of blood were withdrawn both at the end of the 3-minute period of arterial occlusion before release of the cuff and 20 seconds after its release. The mean fibrinolytic activity was a little higher in the sample drawn after restoration of the circulation (mean rise 0.7 unit-Table 2).

Table 1 Effect of venous occlusion or arterial occlusion for 3 minutes on fibrinolytic activity

\begin{tabular}{lllll}
\hline Subject & \multicolumn{4}{l}{ Fibrinolytic activity (units) } \\
\cline { 2 - 5 } & $\begin{array}{l}\text { Without } \\
\text { arterial } \\
\text { occlusion }\end{array}$ & $\begin{array}{l}\text { With arterial } \\
\text { occlusion }\end{array}$ & $\begin{array}{l}\text { Without venous } \\
\text { occlusion }\end{array}$ & $\begin{array}{l}\text { With yenous } \\
\text { occlusion }\end{array}$ \\
& & & & \\
\hline 1 & 6.6 & 6.8 & 5.0 & 18.0 \\
2 & 4.9 & 4.8 & 4.8 & 12.5 \\
3 & 3.0 & 2.6 & 2.6 & 5.2 \\
4 & 4.5 & 4.5 & 4.5 & 12.0 \\
Means & 4.8 & 4.7 & 4.2 & 11.9 \\
\hline
\end{tabular}

Table 2 Comparison of fibrinolytic activity after arterial occlusion for 3 minutes before and after restoration of the circulation

\begin{tabular}{lll}
\hline Subject & \multicolumn{2}{l}{ Fibrinolytic activity (units) } \\
\cline { 2 - 3 } & $\begin{array}{l}\text { At end of period of } \\
\text { arterial occlusion }\end{array}$ & $\begin{array}{l}\text { After restoration of } \\
\text { circulation }\end{array}$ \\
\hline 1 & 6.8 & 6.8 \\
2 & 4.2 & 5.4 \\
3 & 4.4 & 3.0 \\
4 & 4.0 & 7.0 \\
Means & 4.9 & 5.6 \\
\hline
\end{tabular}

ARTERIAL OCCLUSION AND LOCAL EXERCISE In a comparable series of observations, active exercise was undertaken during the period of arterial occlusion. Table 3 shows that exercise resulted in
Table 3 Comparison of fibrinolytic activity after arterial occlusion plus exercise for 3 minutes before and after restoration of the circulation

\begin{tabular}{llll}
\hline Subject & \multicolumn{3}{l}{ Fibrinolytic activity (units) } \\
\cline { 2 - 4 } & $\begin{array}{l}\text { Without } \\
\text { vascular } \\
\text { occlusion }\end{array}$ & $\begin{array}{l}\text { At end of period } \\
\text { of arterial occlusion } \\
\text { with exercise }\end{array}$ & $\begin{array}{l}\text { After restoration } \\
\text { of circulation }\end{array}$ \\
\hline 1 & 4.7 & 4.6 & 7.0 \\
2 & 6.6 & 6.3 & 8.6 \\
3 & 6.4 & 7.2 & 11.8 \\
4 & 5.1 & 5.8 & 6.9 \\
Means & 5.7 & 6.0 & 8.6 \\
\hline
\end{tabular}

little alteration in fibrinolytic activity during the period of arterial occlusion, but that after restoration of the circulation a rise in activity ( 2.6 units) was observed.

\section{Discussion}

Vascular endothelium has been shown to be rich in an activator of plasminogen (Todd, 1959), and it is thought that this may be the source of circulating plasminogen activator; the mechanism controlling its release into the blood is not known. Generalised muscular exercise is a well-known stimulus for the appearance of increased levels of plasma plasminogen activator. Exercise is associated with energy expenditure and the appearance of the end-products of the metabolic process providing this energy; additionally, exercise is associated with increased blood flow through the muscle vascular bed. It is therefore possible that increased levels of plasminogen activator after exercise reflect its release induced by metabolic processes, by the increased blood flow over blood vessel endothelium, or both.

Neither Kwaan and McFadzean (1956) nor Sherry and his colleagues (1959) found that venous occlusion alone increased fibrinolytic activity, but they reported that ischaemia produced by complete arterial occlusion resulted in a rise in activator levels. In complete contrast, our experiments indicate that cessation of blood flow produced by arterial occlusion for 3 minutes does not alter activator levels while venous occlusion alone results in a marked rise. During arterial occlusion by sphygmomanometer cuff total venous occlusion is an inevitable accompaniment, but the venous system remains undistended as no blood flow occurs. During venous occlusion alone marked distension of the superficial veins occurred as arterial flow into the arm was not interrupted. It seemed possible, therefore, that the rise in activator levels noted after venous occlusion alone was due to continued blood flow into the limb with distension of the vascular bed. 
Active exercise without occlusion is associated with a marked rise in activator levels, while passive exercise is accompanied by a smaller, but significant, such increase. Arterial occlusion during the period of muscle exercise abolished this increase, but increased levels were noted in venous blood flowing just after restoration of the circulation.

If the activator appearing in the plasma after venous occlusion and exercise is derived from one source our experiments allow conclusions to be drawn on the mechanism of its release. The factor common to the situations in which no rise in activator level occurred is complete arterial occlusion; this abolished the rise in activator expected after muscular exercise and also that expected after venous occlusion (arterial occlusion induced by sphygmomanometer is, of course, inevitably accompanied by complete venous occlusion). This suggests strongly that ischaemia and the end products of metabolism do not directly trigger the release of plasminogen activator. In contrast, the factor associated with a rise in activator level after exercise and venous occlusion is maintenance of the blood flow into the limb. This suggests that blood flow over vascular endothelium, possibly through channels unperfused at rest but opened up by exercise or the distension consequent on venous occlusion, is of prime importance in initiating the appearance of plasminogen activator in the plasma.

This does not mean that arterial occlusion and the products of ischaemic metabolism cannot indirectly induce a rise in plasminogen activator in the blood. The rise in activator noted in our experiments on re-establishment of blood flow after arterial occlusion with or without exercise could well be due to the increased blood flow occurring after re-establishment of the circulation to the ischaemic muscles.

\section{References}

Biggs, R., Macfarlane, R. G., and Pilling, J. (1947). Observations on fibrinolysis: experimental activity produced by exercise or adrenaline. Lancet, 1, 402-405.

Clarke, R. L., Orandi, A., and Cliffton, E. E. (1960). Induction of fibrinolysis by venous obstruction. Angiology, 11, 367-370.

Kwaan, H. C. and McFadzean, A. J. S. (1956). On plasma fibrinolytic activity induced by ischaemia. Clinical Science, 15, 245-257.

Nilsson, I. M. and Olow, B. (1962). Fibrinolysis induced by streptokinase in man. Acta Chirurgica Scandinavica, 123, 247-266.

Ogston, D. and Fullerton, H. W. (1961). Changes in fibrinolytic activity produced by physical activity. Lancet, 2, 730-733.

Sherry, S., Lindemeyer, R. I., Fletcher, A. P., and Alkjaersig, N. (1959). Studies on enhanced fibrinolytic activity in man. Journal of Clinical Investigation, 38, 810-822.

Todd, A. S. (1959). The histological localisation of fibrinolysin activator. Journal of Pathology and Bacteriology, 78, 281-283. 